\title{
SOBRE A CISÃO ENTRE SUJEITO E OBJETO, SEGUNDO THEODOR W. ADORNO: QUESTÕES PARA A EDUCAÇÃO DO CORPO $^{1}$
}

\author{
Jaison José Bassani* \\ Alexandre Fernandez Vaz ${ }^{* *}$
}

\begin{abstract}
RESUMO
Tomando a obra do filósofo alemão T. W. Adorno como referência principal de pesquisa, o presente trabalho se dedica a uma reflexão epistemológica e pedagógica sobre o tema do corpo e algumas de suas expressões, em especial, no que se refere a um dos motivos originais da constituição da civilização ocidental e do conhecimento sobre esse mesmo processo, a cisão entre sujeito e objeto. Ao considerar as consequências daquela cisão para outra, a entre corpo e espírito (Geist), os resultados dessa investigação apontam para os processos de reificação da espontaneidade corporal e de esquecimento da natureza no sujeito, considerando suas implicações no contexto da expressão mimética. A forma ambígua como tais processos se materializam no esporte e na educação do corpo por meio dele, revelam também indicações para pensar o ensino das práticas corporais como rememoração da natureza no sujeito.
\end{abstract}

Palavras-chave: Sujeito e objeto. Mimesis. Subjetivação. Educação do corpo.

\footnotetext{
* Doutorado em Educação pela Universidade Federal de Santa Catarina (UFSC). Professor do Departamento de Educação Física da Universidade Federal de Santa Catarina e do Programa de Pós-Graduação em Educação da Universidade Federal do Paraná (UFPR). E-mail: jaisonbassani@uol.com.br

** Doutorado em Ciências Humanas e Sociais pela Universidade de Hannover (Alemanha). Professor dos Programas de Pós-Graduação em Educação e Interdisciplinar em Ciências Humanas da Universidade Federal de Santa Catarina (UFSC).E-mail: alexfvaz@uol.com.br

$1 \mathrm{O}$ trabalho apresenta resultados parciais dos projetos Corpo e rememoração da natureza no sujeito: uma investigação na dimensão pedagógica da filosofia de Theodor W. Adorno, financiado pelo CNPq (Processo n. 400681/2009-9, Edital MCT/CNPq 02/2009) e Teoria Crítica, Racionalidades e Educação III, financiado pelo CNPq (Processos n. 309892/20104, 475236/2011-4).
} 


\begin{abstract}
On Scission between Subject and Object by T. W. Adorno: Questions for Education of Body Regarding the work of the German Philosopher T. W. Adorno, this paper is a epistemological and pedagogic reflection about body and some of its expressions, specially referring to an original motive of civilization and the knowledge about it: the scission between subject and object. The consequences of this process are considered in terms of a correlate one: that between body and mind (Geist). The results point out the reification of body spontaneity and the forgetting of nature in subject, specially in mimetic expression. The ambiguous form of those processes that places itself in sport and education through body, suggests something to corporal practices as remembrance of nature in subject.
\end{abstract}

Keywords: Subject and Object. Mimesis; Subject Process. Education of Body.

\title{
Introdução
}

Se muitos dos esforços pedagógicos despendidos pela civilização ocidental, que encontra na escola um espaço importante de realização, se destina ao domínio e controle do corpo e suas expressões, como mostram tanto os estudos da história cultural ${ }^{2}$, quanto parte importante da historiografia da educação ${ }^{3}$, as raízes desse processo devem ser buscadas, se seguirmos as indicações de Adorno, no movimento de esclarecimento (Aufklärung), conduzido e condutor da humanidade desde tempos imemoriais, no qual se inaugura uma cisão cara à nossa tradição: aquela que separa trabalho intelectual de trabalho corporal, espírito de corpo, sujeito de objeto.

2 Entre outros, podemos citar os excelentes volumes da História da vida privada, organizada em cinco tomos por Philippe Aries e Georges Duby (2009).

3 A análise de parte da produção historiográfica do campo da Educação e da Educação Física no Brasil, com destaque especial para os trabalhos de Faria Filho (2000), Gondra (2004), Gondra; Rocha (2000), Taborda de Oliveira (2007), Vago (2004), Linhales (2006), revela, entre outros aspectos, o quanto essa cisão corpo-espírito é cara aos processos de subjetivação materializados sob a forma de programas e propostas curriculares para a escola e as instituições de atendimento à pequena infância. 
De acordo com a conhecida argumentação presente no livro escrito por Adorno e Max Horkheimer $(2003 ; 1985)^{4}$ durante a década de 1940, Dialética do esclarecimento, pode-se dizer que o processo de racionalização ocidental - ou o esclarecimento - do qual a constituição da subjetividade é simultaneamente requisito e decorrência, tem início quando o humano se "separa" da natureza para poder dominá-la. A preocupação central dos autores, no contexto dessa obra, reside menos na circunscrição do problema da Aufklärung aos quase seiscentos anos que nos separam da Renascença italiana (DUARTE, 1997), ${ }^{5}$ do que na pergunta em relação ao conteúdo desse projeto, que tornado intemporal - mas não a-histórico - se objetiva "[...] desde a primeira vez em que, calculadamente, o homem contemplou o mundo [a natureza] como presa." (HORKHEIMER, 2000, p. 176).

Como indicam Adorno e Horkheimer, essa separação original não se dá apenas em relação à natureza externa, mas também a do próprio corpo, interna. Ao alhear-se daquela para poder dominá-la e operacionalizá-la, o humano acaba se tornando também objeto, na medida em que é parte (da) natureza. Aquilo que temos de natureza, mesmo que inevitavelmente mediado pela cultura, pela linguagem - nosso corpo e suas expressões - também é, na forma das paixões e indeterminações, visto como algo ameaçador e desconhecido, e que, portanto, precisa ser dominado. Foi a racionalidade ocidental que instruiu homens e mulheres a dominarem seus impulsos a ponto de poderem cada vez mais contribuir, por meio do seu trabalho - o processo contínuo de transformação deliberadamente humana da natureza -, para construir a civilização e os benefícios, incluindo a segurança e as riquezas, que ela é capaz de gerar. Ao partilhar da formação da cultura, cada um pôde, nesse processo de domínio de sua dimensão corporal, de seus sentimentos, de seus impulsos, formar-se sujeito consciente de sua própria

4 Todas as citações de Theodor W. Adorno realizadas neste trabalho referem-se à edição digital (Digitale Bibliothek Band 97 - Biblioteca Digital v. 97) das obras completas (Gesammelte Schriften). O número da página indicado corresponde à paginação da edição digital. Após o ponto e vírgula, acrescenta-se a referência da tradução correspondente em língua neolatina, notadamente o português e o espanhol.

5 No mesmo sentido, o tradutor brasileiro da obra, Guido Antônio de Almeida (1985, p. 7-8), optou, conforme esclarece em nota preliminar no livro, por esclarecimento e não por iluminismo para o correspondente alemão Aufklärung, uma vez que a segunda expressão faria pensar, mais diretamente, na experiência intelectual dos séculos das luzes. 
individualidade (HORKHEIMER; ADORNO, 2003; 1985; FREITAS, 2003). Dito de outra forma, a relação com o corpo representa um momento fundamental da cisão entre sujeito e objeto, que se afigura neste caso, entre uma dimensão não corporal (espírito - Geist), que exerce senhorio sobre o corpo, o próprio e o de outros, objeto a ser conhecido e controlado.

Considerando o quadro acima, o presente trabalho se dedica a uma reflexão sobre o tema do corpo e algumas de suas expressões, em especial no que se refere a um dos motivos originais da constituição da civilização ocidental e do conhecimento sobre esse mesmo processo, a cisão entre sujeito e objeto. Longe da pretensão de esgotar a temática, o texto procura, ao recorrer à obra de Theodor W. Adorno, considerar algo das consequências daquela cisão para outra, a entre corpo e espírito (Geist), de forma a elucidar aspectos da educação do corpo na sociedade contemporânea.

Como reflexão que se pretende simultaneamente epistemológica e pedagógica, o artigo trata de um detalhamento da tese da separação violenta entre corpo e espírito, sujeito e objeto, e suas consequências para a formação subjetiva, segundo se apresenta na interpretação que Horkheimer e Adorno (2003; 1985), desenvolvem nos fragmentos filosóficos da Dialética do esclarecimento e em outros dos textos que compõem a mesma constelação conceitual e analítica com esse canônico livro.

Para tentar cumprir esse propósito, iniciamos, na sequência, com a descrição do processo imemorial de domínio da natureza e formação do eu, constituído pela cisão de uma dimensão subjetiva em relação à outra que seria objetiva, com suas implicações e contradições. Logo após, tratamos dos processos de reificação da espontaneidade corporal e do esquecimento da natureza no sujeito, considerando suas implicações no contexto da expressão mimética. Por fim, observamos o esporte como momento contemporâneo exemplar da educação do corpo, com vistas a elucidar alguns dos paradoxos derivados daquela cisão original antes mencionada, entre sujeito e objeto.

\section{Domínio da natureza e formação do eu}

Modelar no que diz respeito ao processo de constituição da racionalidade e da civilização ocidental, no qual inauguramos em nós mesmos 
a dolorosa cisão sujeito-objeto, é a particular interpretação que Adorno e Horkheimer fazem da obra de Homero, a Odisséia, tomada, no contexto da Dialética do esclarecimento, como um documento filosófico, um textochave na medida em que representa "um dos mais precoces e representativos testemunhos da civilização burguesa ocidental" (HORKHEIMER; ADORNO, 2003, p. 1101-1102; 1985, p. 15-6). ${ }^{6}$ Nela, o comandante guerreiro Ulisses é mostrado em seu percurso de retorno à Ítaca, sua terra natal, como o protótipo do individuo burguês (HORKHEIMER; ADORNO, 2003, p. 1177; 1985, p. 53), na medida em que as forças míticas e os perigos que precisou enfrentar para retornar à sua pátria representariam, simbolicamente, as forças naturais que o humano precisou vencer e dominar para constituir-se como sujeito esclarecido. Ulisses vence as divindades que encontra em sua viagem, as quais constituem uma ameaça mortal para ele - tal como as forças da natureza em relação ao ser humano -, não por ser fisicamente mais forte, mas porque é mais astuto. Ele só sobrevive à viagem justamente porque se sabe fisicamente fraco, exercendo o cálculo, o senhorio e a previsibilidade sobre si, seu próprio corpo, seus impulsos, sua natureza interna, como testemunha o episódio do canto das Sereias. Na medida em que seu navio se aproxima das ilhas rochosas habitadas por esses seres que são um tanto peixes-pássaros (demarcando o momento de bestialização, de descontrole da natureza) outro tanto mulheres (objeto de domínio na sociedade patriarcal) cujo canto mágico é capaz de enfeitiçar os sentidos humanos, levando aquele que o ouve a se atirar no mar atrás dos seus encantos, Ulisses ordena que seus remadores o amarrem ao mastro do navio, de tal modo que possa ouvir o canto sedutor sem que se jogue ao mar e pereça. Exige também que seus comandados, que devem continuar remando, tapem os ouvidos com cera para que não ouçam nem o canto enfeitiçador daquelas fadas, nem os suplícios de seu senhor ordenando que o soltem. Para poder ludibriar tanto essas quanto às demais divindades que encontra em seu périplo, como a semideusa Circe, os comedores de lótus, o ciclope Polifemo, entre outras, e afirmar-se como sujeito, Ulisses precisou, antes de tudo, dominar seu próprio corpo, tornando-o objeto de sua astúcia, de sua razão.

${ }^{6}$ Sobre o lugar da Odisséia de Homero no contexto da Dialética do esclarecimento, consultar, entre outros, Gagnebin (2006, p. 13-28). 
A formação do sujeito e do indivíduo - essa categoria moderna que se combina e se opõe à sociedade - prefigurada no herói homérico, se dá a partir de uma cisão interna bastante acentuada, que se estabelece entre sua intelectualidade, de um lado, e por sua corporalidade desejante, de outro (FREITAS, 2003, p. 28). É importante destacar que a relação entre sujeito e objeto aqui aludida, segundo nos ensina Adorno (2003, p. 8630-8631; 1995b, p. 182-183), é simultaneamente real e fictícia. Real porque se materializa, por exemplo, no âmbito da educação, nas lições pedagógicas de Platão (2004) na República ou nas recomendações de Comenius (2006) em sua Didática $\mathrm{Magna}^{7}$, nas quais se prescrevem práticas distintas e quase independentes para o corpo e para o espírito, mas também porque denuncia uma cisão ancestral, fundadora da racionalidade, fonte de muito sofrimento. Fictícia porque se trata de uma arbitrariedade histórica do sujeito em relação ao objeto, seu outro também em si mesmo, uma vez que só artificialmente - e com violência - ele pode separar-se e esquecer-se de sua própria natureza - difusa, arcaica, misturada, indefinida, mitológica, perigosa.

Cada ser humano, para ingressar na civilização, precisa reprimir uma parte considerável de seus impulsos, sonhos, fantasias e de muito daquilo que lhe é mais caro, mais valioso, cuja satisfação imediata lhe traria plenos prazeres (FREITAS, 2003, p. 28). Se esse é, por um lado, o tributo que se paga para que seja possível a constituição da racionalidade e, portanto, da civilização e da própria história, conforme os ensinamentos de Freud (1997), por outro, traz consigo o mal-estar de que uma dívida foi excessivamente paga, e de que aquilo que há de natureza no humano foi, de alguma forma, traído (VAZ, 1999, p. 97). Isso porque, explicam os autores da Dialética do esclarecimento, o sacrifício celebrado em nome do sujeito e da civilização pela renúncia representa sempre uma perda maior do que os ganhos dele auferidos. "A história da civilização", afirmam Horkheimer e Adorno (2003, p. 1191-1192; 1985, p. 61), "é a história da introversão do sacrifício, ou por outra, a história da renúncia.

\footnotetext{
7 Sobre os vínculos entre formação corporal e intelectual na Didática Magna, conferir Lovisolo (1999).
} 
Quem pratica a renúncia dá mais de sua vida do que lhe é restituído, mais do que a vida que ele defende." 8

Entretanto, apesar de doloroso, esse processo representa, para Adorno (2003), antes de tudo, um momento fundamental no percurso do esclarecimento e na tentativa de romper com o ciclo inescapável e cego do mundo mitológico. Se, por um lado, Adorno (2003) se coloca como crítico severo da separação absoluta entre sujeito e objeto, especialmente quando essa cisão oculta o domínio velado - mas implacável - do primeiro sobre o segundo, e que encontra, do ponto de vista filosófico, expressão magníloqua no idealismo e no positivismo, por outro, é igualmente verdade que o filósofo frankfurtiano sempre foi hostil a toda e qualquer espécie de nostalgia em relação a uma fase "pré-histórica" que seria supostamente harmônica. Ainda que o Romantismo tenha-lhe sido uma influência marcante - observável, com bastante força, por exemplo, em suas anotações sobre a degradação da vida privada na Minima Moralia (ADORNO, 2003, p. 1644-2178; 1993), na qual se pode ler suas profundas críticas ao perecimento de um sujeito que ainda sobrevivia no início da cultura burguesa - o fato é que para Adorno, conforme aponta Jay (1988, p. 60), todo empreendimento que lamenta as origens perdidas da unidade entre a humanidade e o mundo (natureza) - mas também que identifica a utopia com a futura realização dessa unidade - revela-se não apenas equivocado, mas, além disso, potencialmente regressivo, uma vez que "[...] a obliteração da distinção entre sujeito e objeto significaria, efetivamente, a perda da capacidade de reflexão" (JAY, 1988, p. 60).

8 Este é um tema que remete a tradição frankfurtiana às obras de Freud e Nietzsche. Em O Mal-estar da civilização, Freud (1997) expõe aquilo que seria uma condição inevitável do processo civilizador, qual seja, a renúncia pulsional e, com ela, o decorrente mal-estar que facilmente deriva em trauma e violência. Por outro lado, no livro Genealogia da moral, Nietzsche (1998) já elaborara suas teses sobre a crueldade decorrente das formas de subjetivação a que se vê obrigado o "homem contemporâneo", asceta, endurecido, que volta à naturalidade uma vez esquecida de si e da qual fazia parte. Sobre as afinidades e distanciamentos de Freud e Nietzsche na análise do problema do surgimento da cultura, da moralidade e do sentimento de culpa a partir da relação entre as noções de memória, esquecimento e repetição, elementos comuns no universo categorial de ambos os autores, consultar o trabalho de Giacóia Jr. (2001). 
Particularmente importante nesse contexto de apreensão da relação sujeito-objeto é a análise que Adorno e Horkheimer fazem da passagem do livro de Homero na qual Ulisses e seus remadores encontram os lotófagos, os comedores de lótus. Aqueles que provam do seu alimento sucumbem tal como os que ouvem o canto das Sereias ou aqueles que, se tocados pela vara mágica da semideusa Circe, transformam-se em porcos amestrados. No entanto, ao contrário do que acontece no caso do embate com estas e outras entidades mitológicas da narrativa homérica, aqueles que comem o lótus não se encontram sob uma ameaça mortífera: “[...] nenhum mal é feito a suas vítimas", já que "a única ameaça é o esquecimento e a destruição da vontade" (HORKHEIMER; ADORNO, 2003, p. 1203; 1985, p. 67). O lótus, espécie de narcótico, condena aqueles que provam da sua doçura, como os marinheiros de Ulisses, a um "[...] estado primitivo sem trabalho e sem luta na "fértil campina"” (HORKHEIMER; ADORNO, 2003, p. 1203; 1985, p. 67), sem vontade alguma de partir desse lugar. Condena, consequentemente, à regressão a uma fase anterior a todo e qualquer tipo de produção (trabalho), a um estado supostamente idílico de fusão com a natureza e, portanto, de projetada felicidade e ausência de qualquer carência, de todo sofrimento. No entanto, advertem Adorno e Horkheimer, "esse idílio é na verdade a mera aparência da felicidade, um estado apático e vegetativo, pobre como a vida dos animais e no melhor dos casos a ausência da consciência da infelicidade" (HORKHEIMER; ADORNO, 2003, p. 1203; 1985, p. 67). Tanto essa interpretação da passagem do herói Ulisses e seus comandados pela ilha dos comedores de lótus, quanto o fragmento a seguir, retirado do ensaio Sobre sujeito e objeto (o título aqui não menos importante), atestam o quanto Adorno permaneceu cético em relação a qualquer perspectiva que visasse à restauração de uma unidade pré-reflexiva, de um estado mitológico pré-subjetivo:

[...] a imagem de um estado originário, temporal ou extra-temporal, de feliz identificação de sujeito e objeto, é romântico; por longo tempo, projeção da nostalgia, hoje reduzida à mentira. A identificação, antes que o sujeito se formasse, foi o estremecimento do cego nexo natural, o mito; as grandes religiões tiveram seu conteúdo de verdade no protesto contra ele. Além do mais, indiferenciação não é unidade; 
esta exige, já segundo a dialética platônica, diversidade, cuja unidade ela constitui. $\mathrm{O}$ novo horror, o da separação, transfigura, diante daqueles que o vivem, o antigo, o caos, e ambos são o sempre-idêntico [Immergleiche] (ADORNO, 2003, p. 8630-8631; 1995b, p. 183).

Se essa separação não deve ser propriamente celebrada, por outro lado, não pode ser esquecida, uma vez que isso significaria, como destacado anteriormente, recalcar o sofrimento que lhe dá origem e que dela se origina. Para o filósofo frankfurtiano, o estado de indeterminação entre sujeito e objeto é tão pernicioso quanto o da sua total separação, pregada, no âmbito da teoria do conhecimento, pelo positivismo. A indiferenciação, em contrapartida, corresponde exatamente ao mundo do mito. Sua possível superação depende menos da vontade do observador do que da transformação das condições históricas que a produziram: "se fosse permitido especular sobre o estado de reconciliação [Versöhnung]", afirma cautelosamente Adorno (2003), "não caberia imaginá-lo nem sob a forma de indiferenciada unidade de sujeito e objeto nem sob a de sua hostil antítese; antes, a comunicação do diferenciado [Unterschiedenen]" (ADORNO, 2003, p. 8631-2; 1995b, p. 184). Esta é uma reflexão que faz convocar um momento de indeterminação, de mimesis e de recordação da natureza no sujeito (ADORNO, 2003, p. 2823-3726;2009), exemplarmente mencionado em Dialética do esclarecimento (HORKHEIMER; ADORNO, 2003; 1985) na forma do riso: simultaneamente uma manifestação do nosso descontrole e, portanto, do mito que nos governa e para o qual pouco podemos oferecer como oposição - frequentemente associada ao preconceito e ao horror mas também uma expressão de algo espontâneo, ainda não inteiramente dominado pelos ardis reificadores da razão instrumental.

\section{Corpo, mimesis: reificação e esquecimento}

O problema dessa relação exposta no item anterior se encontra não exatamente no espaço de diferenciação entre humano e natureza, entre sujeito e objeto, mas na denegação/superação/esquecimento de toda forma de mimesis, de mistura, de indiferenciação originária da própria subjetividade. Em outras palavras, a constituição do sujeito autônomo, 
do eu (ego) durável, diferenciado, indivíduo, só foi possível na medida em que este se apoderou da natureza. No entanto, como condição para o domínio da natureza externa e em nome da autoconservação do sujeito e de uma razão totalitária que não permite um fora dela mesma, um momento que lhe seja exterior e que pudesse, portanto, opor-se-lhe como outro, foi preciso que o ser humano, o eu esclarecido em formação, dominasse, ou, melhor dizendo, esquecesse, alienasse a sua própria porção de natureza, sua natureza interna, seu corpo. O próprio conhecimento erigido dessa dominação, ou seja, a capacidade de manipulação técnica da natureza acaba reagindo sobre a subjetividade que se formou a partir dessa atividade dominadora. Nesse sentido, o controle da natureza está ligado à violência introvertida no humano, ao esquecimento do sujeito sobre sua própria natureza, sua vitalidade mais originária: "o preço da dominação não é meramente a alienação dos homens com relação aos objetos dominados; com a coisificação [Versachlichung] do espírito, as próprias relações dos homens foram enfeitiçadas, inclusive as relações de cada indivíduo consigo mesmo" (HORKHEIMER; ADORNO, 2003, p. 1146; 1985, p. 40).

É neste quadro que se coloca o fundamental conceito de Verdinglichung (reificação/coisificação), peça-chave no arcabouço teórico adorniano, mas também de outros intelectuais vinculados à Teoria Crítica, dentre eles, especialmente Horkheimer e Hebert Marcuse. Embora não seja possível no contexto deste trabalho aprofundar o modo como Adorno opera com este conceito, importa destacar, conforme o faz Jay (1988, p. 53-74), que apesar do filósofo frankfurtiano empregar essa categoria num sentido muito próximo daquele utilizado por Georg Lukács ${ }^{9}$ no livro

9 Como exemplo, podemos citar a seguinte passagem do texto Introdução à controvérsia sobre o positivismo na sociologia alemã, na qual Adorno procura demarcar a diferença fundamental do conceito de sociedade empregado pela Teoria Crítica daquele da sociologia positivista: "Eis aqui a diferença mais profunda entre uma teoria crítica da sociedade e o que na linguagem corrente é denominado sociologia: uma teoria crítica, apesar de toda experiência de coisificação [Verdinglichung], e mesmo justamente ao exteriorizar essa experiência, se orienta pela ideia da sociedade como sujeito, enquanto a sociologia aceita a coisificação [Verdinglichung], repetindo-a em seus métodos, perdendo assim a perspectiva em que a sociedade e sua lei unicamente se revelam" (ADORNO, 2003, p. 5278; 1991, p. 131). Outro momento bastante importante nesse sentido, surge no ensaio Educação após Auschwitz, especialmente na advertência que Adorno faz em relação às pessoas que se enquadram cegamente nos diversos tipos de coletivos, convertendo a si próprios em algo 
História e consciência de classe (LUKÁCS, 2001), como objetivação alienada da subjetividade, transformação de um processo vivo em coisa morta, o fato é que o conceito de reificação parece alcançar em Adorno um fundo mais amplo, abarcando não apenas a relação de domínio no contexto da cisão representada pelas classes sociais e pela subsunção do trabalho à forma mercadoria, mas também aquela do humano com a natureza, tanto interna quanto externa. Nesse sentido, quando Adorno utiliza tal categoria, ela diz respeito à supressão da heterogeneidade do objeto em nome da identidade do conceito (JAY, 1988, p. 63), cuja origem remonta, em termos epistemológicos, à separação imemorial do humano - sujeito em formação - em relação à natureza, ao mundo material: "uma vez radicalmente separado do objeto", assevera Adorno em Sobre Sujeito e objeto, "o sujeito já reduz este a si; o sujeito devora o objeto ao esquecer o quanto ele mesmo é objeto" (ADORNO, 2003, p. 8630; 1995b, p. 183). Em outra passagem, extraída do aforismo Le prix du progrès - O preço do progresso, que compõe a seção de Notas e Esboços da Dialética do esclarecimento, Adorno e Horkheimer expõem essa interpretação de maneira ainda mais eloquente ao afirmarem que

o espaço que nos separa dos outros significaria, para o conhecimento, a mesma coisa que o tempo que se intercala entre nós e o sofrimento do nosso próprio passado, a saber, uma barreira insuperável. Mas a dominação perene da natureza, a técnica médica e não-médica, tira sua força dessa cegueira; só o esquecimento a torna possível. A perda da lembrança como condição transcendental da ciência. Toda reificação é um esquecimento [Alle Verdinglichung ist ein Vergessen] (HORKHEIMER; ADORNO, 2003, p. 1522; 1985, p. 214, grifo meu).

\footnotetext{
como um material, e que corresponderia, segundo o autor, a disposição de tratar os outros como sendo uma massa amorfa. Para as pessoas que se comportam dessa maneira - entre elas, os tipos característicos do mundo de Auschwitz como os "Eichmanns", "Himmlers" e "Mengeles"-, Adorno utiliza a expressão manipulativen Charakter, caráter manipulador (ADORNO 2003, p. 8531; 1995a, 129), o qual, se fosse obrigado a resumi-lo a uma fórmula, Adorno (2003, p. 8533; 1995a, p. 130) o denominaria verdinglichtes Bewußtsein, consciência coisificada. Para ele, as pessoas desse tipo tornam-se, por assim dizer, iguais a coisas. Em seguida, na medida em que conseguem, reduzem também os outros à condição de coisa.
} 
Condição necessária para o progresso da civilização, a cegueira da dor e do sofrimento diante da violência impingida à natureza - $O$ esquecimento do sofrimento do nosso passado - acaba voltando-se contra o próprio humano, como uma "vingança" pelos "obscuros caminhos" a que a natureza fora conduzida pela mão armada do homem. Nesse percurso - que não é outro senão o da Aufklärung - a dissolução dos mitos animistas, que haviam atribuído alma às coisas, pelo progresso técnico, acabou por submeter-se a uma mistificação ainda mais terrível: a de um mundo que transforma não apenas a alma, mas também o corpo do homem em coisa. Ao esquecer, não sem uma nova dose de violência, o seu compartilhamento com a natureza, o homem regride ao mito, tornandose como que enfeitiçado (HORKHEIMER; ADORNO, 2003, p. 1105-71; 1985, p. 19-52; LÖWY; VARIKAS, 1992, p. 210). Se a crítica dialética dos frankfurtianos ao progresso é radical, ela não deve ser confundida, por outro lado, a um discurso saudosista ou passadista que atribuiria ao desenvolvimento tecnológico e científico a condição de algo "demoníaco", para a qual o único remédio seria deles livrar-se (BASSANI; VAZ, 2008). Sem ter condições de aprofundar essa discussão sobre a relação progressoregressão, gostaríamos de destacar, assim como o fazem Horkheimer e Adorno $(2003 ; 1985)$ no prefácio da Dialética do esclarecimento, que da mesma forma que não há dúvida que a liberdade no âmbito da sociedade é inseparável do pensamento esclarecedor, também a ideia de progresso da humanidade não está dissociada do avanço dos meios ou dele pode prescindir. A recusa de Adorno, assim como de outros intelectuais da "primeira geração" de frankurtianos (MARCUSE, 2001, 1999; 1973; BENJAMIN, 1991, 1985; HORKHEIMER, 2000, 1990) em dissociar progresso dos meios e progresso da humanidade está vinculada à postura ética derivada do próprio projeto da "dialética do esclarecimento", medida em que destacam Löwy e Varikas (1992, p. 208), não está no grau de desenvolvimento dos conhecimentos e nem mesmo no seu potencial prévio de emancipação, mas na medida em que esses conhecimentos realizam de fato essa promessa de emancipação. Essa postura de não dissociar progresso técnico e humano, mas também de não confundi-los, revela um fundo duplo ou um duplo caráter de uma dinâmica que, como o próprio Adorno (2003, p. 1933; 1993, p. 129) afirma, "sempre desenvolveu o potencial da liberdade ao mesmo tempo em que a realidade efetiva da opressão". 
É exatamente nesse quadro, no da perpetuação da violência da natureza e do seu ciclo inescapável, que Adorno e Horkheimer afirmarão, no aforismo Interesse pelo corpo, em Dialética do esclarecimento, que o autorrebaixamento do homem a corpus, a objeto, é a forma pela qual a natureza interna ao ser humano, "considerada" pela consciência como seu outro - uma vez esquecida pelo sujeito -, se vinga do fato do homem tê-la diminuída a objeto de dominação, à matéria bruta: "é só a cultura", dizem Adorno e Horkheimer, "que conhece o corpo como coisa que se pode possuir; foi só nela que ele se distinguiu do espírito, quintessência do poder e do comando, como objeto, coisa morta, 'corpus'”, (HORKHEIMER; ADORNO, 2003, p. 1526; 1985, p. 217). A relação de dominação do sujeito sobre o objeto mostra-se, nesse caso, e especialmente em relação ao domínio de si, como sendo o contrário, ou seja, o domínio do objeto, da natureza. Essa fictícia superioridade do sujeito ocorre porque no mesmo instante em que se apresenta à natureza como potência dominadora, converte-se, ele próprio, em coisa, parte da matéria que crê dominar (DUARTE, 1993, p. 170). Esse processo de "naturalização" da subjetividade, fruto da própria atividade dominadora do humano em nome da sua autoconservação física, é expresso da seguinte maneira por Horkheimer e Adorno (2003):

Com a negação da natureza no homem, não apenas o telos da dominação externa da própria natureza, mas também o telos da própria vida se torna confuso e opaco. No instante em que o homem elide a consciência de si mesmo como natureza, todos os fins para os quais ele se mantém vivo - o processo social, o aumento das forcas materiais e espirituais, até mesmo a própria consciência - tornam-se nulos, e a entronização do meio como fim, que assume no capitalismo tardio o caráter de um manifesto desvario, já é perceptivel na proto-história da subjetividade. O dominio do homem sobre si mesmo, em que se funda o seu ser, é sempre a destruição virtual do sujeito a serviço do qual ele ocorre; pois a substância dominada, oprimida e dissolvida pela autoconservação, nada mais é senão o ser vivo, cujas funções configuram, elas tão-somente, as atividades da autoconservação, por conseguinte exatamente aquilo que na verdade devia ser conservado (HORKHEIMER; ADORNO, p. 1190-1191; 1985, p. 60-61, grifo nosso). 
O controle do corpo e suas expressões, assim como a compulsão à crueldade e à destruição em relação a ele, significam para os autores da Dialética do esclarecimento - numa clara referência ao Mal-estar na cultura de Freud (1997) $)^{10}$ - recalcamento e esquecimento daquilo que liga o sujeito à lembrança de sua dimensão "orgânica", materialista, e, por consequência, de uma prototípica unidade com a natureza (HORKHEIMER; ADORNO, p. $1527 ; 1985$, p. 217). Não por acaso, o processo de forja do sujeito - que, como dito, coincide com a constituição da civilização - exigirá a renúncia das relações miméticas, de aproximação e assemelhamento com a natureza.

Adorno e Horkheimer (2003) apresentam o movimento protohistórico de produção mimética: o humano ainda desprovido de subjetividade, quando sentia medo, assemelhava-se e dissolvia-se corporalmente na natureza, confundindo-se com o espaço imóvel a fim de se defender e desviar do perigo. Diluindo-se e fazendo-se "igual" ao amorfo por meio dessa adaptação orgânica, que partilhamos com outros animais - e cujo exemplo mais evidente talvez seja o do camaleão -, nossos ancestrais livravam-se da diferença que trazia o medo (não sentimos medo do semelhante, daquilo que é "idêntico", igual a nós). Também nos rituais mágicos, formas de intervenção sobre a natureza, a mimesis exercia um importante papel, na medida em que o feiticeiro assumia com seus movimentos (numa dança) e suas feições (por meio do uso de uma máscara, por exemplo) a forma das divindades, assemelhando-se a elas para apaziguá-las (HORKHEIMER; ADORNO, 2003, p. 1105-1171; 1985, p. 19-52.)

Na Dialética do esclarecimento, esse procedimento mágicomimético é interpretado, essencialmente, como um comportamento

\footnotetext{
${ }^{10}$ Para Freud (1997, p. 53-4), a civilização teria se originado a partir da adoção pelo homem de uma postura ereta e a consequente "repressão orgânica". Segundo o autor, a partir da adoção da postura ereta, uma "[...] cadeia de acontecimentos teria prosseguimento, passando pela desvalorização dos estímulos olfativos e o isolamento do período menstrual até a época em que os estímulos visuais se tornaram predominantes e os órgãos genitais ficaram visíveis, e, daí, para a continuidade da excitação sexual, a fundação da família e, assim, para o limiar da civilização humana" (FREUD, 1997, p. 54). Inscrito nesse mesmo processo, está a tendência cultural para a limpeza, que, segundo Freud, teria origem no impulso a livrar-se das excreções, que se tornaram desagradáveis aos sentidos. Não por acaso, como destaca o autor, a civilização empregará grande energia no processo de educação das crianças para que aprendam desde muito pequenas a controlar seus esfíncteres.
} 
regressivo. ${ }^{11}$ Conforme destaca Gagnebin (1997, p. 85), a base das análises de Horkheimer e Adorno sobre o tema é constituída fundamentalmente pela leitura da obra de Freud e de etnólogos da época (principalmente os franceses Roger Callois e Marcel Mauss, citados no livro), que compreendiam a mimesis ou como regressão associada à pulsão de morte e ao desejo de dissolução do sujeito no nada (Freud), ou como comportamento regressivo de assimilação ao perigo, como expediente para dele defenderse (etnologia). O essencial, sobretudo, na interpretação etnológica da qual se valem Horkheimer e Adorno, salienta Gagnebin (1997, p. 85-6), relaciona-se ao comportamento do sujeito que, por medo, renuncia a se diferenciar do outro que teme para, ao imitá-lo, suprimir a distância que os separa, a qual permitiria ao inimigo (animal, divindade, fenômeno natural) reconhecê-lo como vítima. A fim de salvar-se, o sujeito desiste, perde-se de si mesmo, assimilando-se fisicamente à natureza inanimada - o espaço representa, como afirmam os autores, a "alienação absoluta" (HORKHEIMER; ADORNO, 2003; p. 1425; 1985, p. 168).

Entretanto, os autores não deixam de destacar, em consonância com a interpretação freudiana, o componente extremamente sedutor e prazeroso que há nessa perda, nesse desejo de dissolução dos limites que, igualmente, constituem o eu, o sujeito. Desejo que remete "à paixão e à sexualidade, ao êxtase religioso e místico, mas também, e inseparavelmente, à dor da loucura e à decomposição da morte." (GAGNEBIN, 1997, p. 86). Nesse contexto, a mimesis representa uma ameaça ao processo de constituição do eu e da própria civilização, que não medirá esforços para solapar, não sem dor e sofrimento, os últimos vestígios desse comportamento:

${ }^{11} \mathrm{O}$ conceito de mimesis aparece de forma complexa ao logo da obra de Adorno. De maneira geral, o tema da mimesis pode ser compreendido em três momentos distintos, mas que compõem uma mesma unidade, uma mesma constelação, como diria Vaz (2007): 1) o conceito diz respeito à autoconservação individual dado pelo assemelhamento à natureza circundante, ao aplacamento do medo das divindades por meio da magia e da dança, e pela denegação/proscrição/esquecimento social do comportamento mimético em favor do pensamento racional; 2) refere-se à degradação da mimesis em mimetismo, em "falsa mimesis" associada à projeção paranóica e sua funcionalização pelos regimes políticos totalitários; e 3) dá conta da relação estética e reconciliatória - que não é, no entanto, unívoca, mas que se coloca em tensão com o distanciamento, entendido como respeito ao outro, ao diferente de si - entre sujeito e objeto, tal como na fruição artística (VAZ, 2007). 
Para a civilização, a vida no estado natural puro, a vida animal e vegetativa, constituía o perigo absoluto. Um após o outro, os comportamentos mimético, mítico e metafísico foram considerados como eras superadas, de tal sorte que a idéia de recair neles estava associada ao pavor de que o eu revertesse à mera natureza, da qual havia se alienado com esforço indizível e que por isso mesmo infundia nele indizível terror. A lembrança viva dos tempos pretéritos [...] fora extirpada da consciência dos homens ao longo dos milênios com as penas mais terríveis (HORKHEIMER; ADORNO, 2003, p. 1151; 1985, p. 42).

A própria razão, segundo procuram argumentar Horkheimer e Adorno ao longo de todo o livro, nasce justamente da tentativa sempre renovada de afastar o medo em relação à natureza desconhecida e da necessidade de suplantar os procedimentos mágico-miméticos, insuficientes e débeis nessa tarefa. O lugar deixado pela proscrição da mimesis passa a ser ocupado, na relação com a natureza, pela regularidade e repetição do procedimento científico e pela fórmula matemática - "a mais sublime modalidade de mimetismo" (HORKHEIMER; ADORNO, 2003, p. 1427; 1985, p. 169) no lugar da magia, que promovia o assemelhamento apaziguador, a técnica, que "efetua a adaptação ao inanimado a serviço da autoconservação" (HORKHEIMER; ADORNO, 2003, p. 1427; 1985, p. 169).

Mas há um tributo bastante caro que precisará ser pago para que o sujeito esclarecido converta-se no outro radical da natureza. Conforme sintetiza Gagnebin (1997, p. 87), tal preço poderia ser descrito como a transformação da mimesis originária, sedutora, prazerosa, mas, ao mesmo tempo, ameaçadora, numa mimesis perversa, índice da dureza do processo pelo qual o sujeito, enrijecido e petrificado, precisou passar: "essa segunda mímesis se constrói sobre o recalque da primeira: ela caracteriza o sujeito que conseguiu resistir a tentação da regressão mas que perdeu, nessa luta tão necessária quanto fatal, a plasticidade e a exuberância da vida originária, quando não perdeu a vida tout court" (GAGNEBIN, 1997, p. 87).

Se a civilização tem origem no gradativo solapamento da mimesis em favor de procedimentos mais eficazes no controle e no domínio da natureza que nos é assustadora, então, o progresso cultural como um todo, incluindo também a educação, reproduz filogenética e ontogenéticamente o 
processo de conversão do comportamento mimético em atitudes racionais. Conforme destaca Horkheimer (2000, p. 118), no ensaio intitulado $A$ revolta da natureza - no qual, aliás, retoma várias problemáticas e análises presentes no Excuso I e no terceiro capítulo do livro escrito com Adorno - o humano "primitivo" assim como aprendeu que pode obter melhores colheitas por meio da agricultura do que pela magia, também o indivíduo moderno, desde o seu nascimento, deve aprender a dominar seus impulsos miméticos e direcioná-los para um objetivo racionalmente definido. Entretanto, na medida em que a razão se transformou ao longo da história primordialmente num instrumento para garantir a autoconservação do sujeito, convertendo-se num poderoso e impiedoso sistema de dominação, na medida em que a renúncia aos impulsos miméticos não conduz à realização das potencialidades humanas e as promessas da razão não são cumpridas, então esse impulso estará sempre à espreita, pronto para emergir nas situações limítrofes com força destruidora. ${ }^{12}$ Nas palavras de Horkheimer e Adorno:

O rigor com que os dominadores impediram no curso dos séculos a seus próprios descendentes, bem como às massas dominadas, a recaída em modos de vida miméticos - começando pela proibição de imagens na religião, passando pela proscrição social dos atores e dos ciganos e chegando, enfim, a uma pedagogia que desacostuma as crianças de serem infantis - é a própria condição da civilização. A educação social e individual reforça nos homens seu comportamento objetivamente enquanto trabalhadores e impede-os de se perderem nas flutuações da natureza ambiente. Toda diversão, todo abandono tem algo de mimetismo. Foi se enrijecendo contra isso que o ego se forjou. É através da sua constituição que se realiza a passagem da mimese refletora para a reflexão controlada. [...] Da assimilação à natureza resta apenas o enrijecimento contra ela (HORKHEIMER E ADORNO, 2003, p. 1427; 1985, p. 169, grifo nosso).

\footnotetext{
${ }^{12}$ Como bem define Horkheimer no texto anteriormente citado, “[...] se não existe outra norma além do status quo, se toda a esperança de felicidade que a razão pode oferecer é preservar o existente tal como ele é e mesmo aumentar suas pressões, o impulso mimético jamais pode ser verdadeiramente superado. Os homens retornam a esse impulso de uma forma regressiva e distorcida" (HORKHEIMER, 2000, p. 119).
} 
Como mostram Horkheimer e Adorno (2003, p. 1424-1436; 1985, p. 168-174) na seção V do terceiro capítulo da Dialética do esclarecimento, é a dominação, especialmente em sua versão nazista, que permite a entronização triunfante do solapamento da mimesis originária e a consagração da mimesis perversa, "mimesis da mimesis" (HORKHEIMER; ADORNO, 2003, p. 1433; 1985, p. 172; GAGNEBIN, 1997, p. 90). Essa versão degradada da mimesis, que, em face da dominação irracional e irrefletida, não é completamente superada, reaparece como tabu em certos gestos e comportamentos, como nas reações corporais idiossincráticas, no descontrole somático na face enrubecida e no suor do cenho franzido frente ao desconhecido, ao corpo estranho. Não foi por acaso que esse arcaísmo do corpo, como lembrança recalcada de reações miméticas originárias, "momentos da proto-história biológica" (HORKHEIMER; ADORNO, 2003, p. 1424; 1985, p. 168), mobilizado politicamente pelo Nacionalsocialismo, demarcado também pelas cifras miméticas que fazem cada um diluir-se da condição de sujeito, ao assemelhar-se às figuras identificadoras do poder: políticos em seus comícios, soldados em uniformes, atletas em seus gestos precisos e potentes (HORKHEIMER; ADORNO, 2003, p. $1433 ; 1985$, p. 172). ${ }^{13}$

Um dos momentos marcantes desse movimento que passa da mimesis genuína à sua face perversa encontra-se no esporte. Não por outro motivo, ele foi convertido num importante veículo de divulgação - mas também de educação - da propaganda e da ideologia nazista. Os Jogos Olímpicos de 1936 em Berlim e o filme a partir deles produzido pela cineasta alemã Leni Riefensthal - Olympia, feito sob encomenda de Hitler, e celebrado por suas inovações técnicas e estéticas ainda

\footnotetext{
${ }^{13}$ Ao permitir e incentivar semelhante comportamento pela liberação das pulsões e pela suspensão do interdito, o Nacional-socialismo promove menos uma reconciliação com a natureza mutilada do que a funcionalização e instrumentalização da própria revolta da natureza - como denominou Horkheimer - não apenas contra as promessas não cumpridas e as renúncias exigidas pelo processo civilizador, mas também, e, sobretudo, contra a própria civilização. Essa "reconciliação às avessas" engendrada pelo nazismo é colocada novamente a serviço da dominação da natureza, bem como das massas que a expressam. "O fascismo", dizem Horkheimer e Adorno, "também é totalitário na medida em que se esforça por colocar diretamente a serviço da dominação a própria rebelião da natureza reprimida contra essa dominação" (HORKHEIMER; ADORNO, 2003, p. 1433; 1985, p. 172).
} 
influentes em toda a cobertura televisiva de eventos esportivos ${ }^{14}$ - são, certamente, os exemplos mais evidentes. Adorno (2003), num cometário feito no texto Anti-semitismo e propaganda fascista (o título aqui não é menos importante!), escrito em 1946 (originalmente em inglês), destacou a afinidade entre os rituais dos comícios políticos nazistas e aqueles dos espetáculos esportivos:

"Espectáculo" es ciertamente la palabra correcta. La actuación del líder sedicente es una interpretación que recuerda al teatro, al espectáculo deportivo, a los denominados resurgimientos religiosos. Resulta característico de los demagogos fascistas el hecho de que fanfarroneen de haber sido héroes del atletismo en su juventud. Así es como se comportan. Gritan y lloran, hacen como si combatieran al mismísimo diablo, y se quitan las chaquetas cuando atacan a "esos poderes sinietros" (ADORNO, 2003, p. 5461; 2004a, p. 374).

\section{Esporte, "saúde", amor-ódio pelo corpo}

O processo imemorial e crescente do domínio da natureza, colocado como condição necessária para a própria civilização, como vimos, pressupõe o controle sobre o corpo como um de seus primeiros degraus. Essa preocupação constante com o domínio de nossa natureza interna pode ser traduzida, entre outros, nos inúmeros conhecimentos, técnicas e discursos que pretenderam não apenas legitimar, mas também operacionalizar o controle sobre o corpo. Direta ou indiretamente, vários desses conhecimentos têm seu balizamento no esporte, e não é sem razão, pois nele o corpo é o instrumento técnico por excelência e, assim como este, como ferramenta, deve potencializar o domínio sobre a natureza, da mesma forma o corpo, em si mesmo, deve ser expressão da natureza convertida em objeto de dominação (VAZ, 2001; 1999). É em parte a partir desse prisma que Adorno vê no esporte uma espécie de estrutura modelar para se compreender a sociedade contemporânea, especialmente

\footnotetext{
${ }^{14}$ Olympia: Parte 1 - Festa do Povo (Olympia), Parte II - Festa da Beleza (Apoteose de Olympia), foi filmado em 1936 e lançado em 1938. Sobre o filme consultar os trabalhos de Almeida (2006) e Wildmann (1998).
} 
no que se refere à relação com a corporalidade, tanto porque nela, assim como naquele, imperaria o princípio do rendimento, quanto porque várias dimensões da vida social, como a política, a arte, a sexualidade e a vida privada estariam, em grande medida por meio dos mecanismos da indústria cultural, se esportivizando (Sportifizierung), ou seja, incorporando os códigos, sentidos e normas daquele (HORKHEIMER; ADORNO, 2003, p. 1256 e p. $1626-1629 ; 1985$, p. 87; 2007, p. 308-310).

Tanto como estrutura modelar, no sentido atribuído por Adorno (2003), quanto como dramatização de diferentes fenômenos sociais, entre eles a guerra, o esporte, ao promover o culto à técnica, aos grandes números e à reificação corporal - e ao supor a rígida separação entre sujeito e objeto, premissa fundamental para que o corpo possa ser tomado como objeto operacional - promove a mimesis do que é morto pela redução do corpo à matéria desprovida de qualidades. Por outra, à condição de máquina, que, como afirma Adorno na Minima Moralia, somente em estado patológico pode a ela assemelhar-se (ADORNO, 2003, p. 1735; 1993, p. 46).

De acordo com as análises de Adorno e Horkheimer, a razão denega furiosamente o corpo e a natureza, ao perseguir justamente o domínio e buscar a regularidade operacional de seus movimentos, mas, como destaca Ramos (2006, p. 21), o corpo e a natureza não podem ser de todo negados e sua "vingança" consiste, justamente, em reduzir a própria subjetividade à repetição mimética, fazendo-a recair na mesma condição da qual tenta, a duras penas, se afastar e diferenciar. Ao recalcar as possibilidades miméticas do indivíduo, a própria razão degrada-se em mimetismo e o indivíduo se torna endurecido e insensível com o mundo e com sua própria corporalidade. Como não podemos nos livrar do corpo, afirmam Adorno e Horkheimer (2003), nós o louvamos quando não podemos golpeá-lo:

Os que na Alemanha louvavam o corpo, os ginastas e os excursionistas, sempre tiveram com o homicídio a mais íntima afinidade, assim como os amantes da natureza com a caça. Eles vêem o corpo como um mecanismo móvel, em suas articulações as diferentes peças desse mecanismo, e na carne o simples revestimento do esqueleto. Eles lidam com o corpo, manejam seus membros, como se estes já estivessem separados. A tradição judia conservou a aversão de medir as pessoas 
com um metro, porque é do morto que se tomam as medidas - para o caixão. É nisso que encontram prazer os manipuladores do corpo. Eles medem o outro, sem saber, com o olhar do fabricante de caixões, e se traem quando anunciam o resultado, dizendo, por exemplo, que a pessoa é comprida, pequena, gorda, pesada (HORKHEIMER; ADORNO, p. 1530-1; 1985, p. 219).

Convertido em objeto de repulsão e atração na civilização ocidental, o corpo torna-se tabu e a relação de amor-ódio por ele impregna toda a cultura moderna, inclusive, nos seus momentos mais insuspeitos, como no âmbito da educação, do lazer (ADORNO, 2003, p. 8474-75; 1995b, p. 74-75) no esporte, nas ciências médicas etc. Na escola, por exemplo, Adorno (2003) refere-se, entre outros aspectos, à existência de dupla hierarquia: uma oficial baseada, sobretudo, no desempenho intelectual, e outra, latente, não honrada pela primeira e, portanto, não-oficial, em que a força física, o "ser homem" e todo um conjunto de aptidões prático-físicas, muitas delas vinculadas à violência, exercem um papel bastante importante (ADORNO, 2003, p. 8505; 1995a, p. 111). ${ }^{15}$ No que se refere à saúde, semelhante análise surge em Minima Moralia, mais especificamente no aforismo $A$ saúde para a morte, no qual Adorno (2003) afirma, num tom muito próximo àquele presente no aforismo Interesse pelo corpo, mas também na quinta seção do capítulo sobre Os elementos do anti-semitismo, que a "doença", ou em termos freudianos - o mal-estar -, da nossa época está inscrita na própria civilização, e, portanto, precisamente naquilo que consideramos "normal":

$\mathrm{Na}$ base da saúde reinante está a morte. Todo o seu movimento assemelha-se aos movimentos reflexos de seres humanos cujo coração parou de bater. Só ocasionalmente as desditosas rugas da testa - testemunho de tensões terríveis e há muito esquecidas -, ou um momento de estupidez pática em meio a uma lógica inalterável, ou um

\footnotetext{
${ }^{15}$ Certamente poderíamos falar em múltiplas hierarquias no universo escolar hoje, como aquela que destaca os menos pobres (o que consomem alimentos nas cantinas e não usufruem da merenda escolar, os que têm mais brinquedos, que variam as roupas a cada dia etc.), os mais bonitos, segundo os padrões de beleza dominantes, entre outras possibilidades (BASSANI; TORRI; VAZ, 2003; VAZ; BASSANI; SILVA, 2002).
} 
gesto de desamparo conservam perturbadoramente os vestígios da vida que se esvaziou. Pois o sacrifício socialmente exigido é tão universal, que ele, de fato, só se torna manifesto na sociedade como um todo e não no indivíduo. A sociedade assumiu, por assim dizer, a doença de todos os indivíduos, e nela, na loucura represada nas camadas fascistas e em todas as inúmeras preformações e mediações destas, a desgraça subjetiva profundamente enterrada no indivíduo integra-se à desgraça objetiva visível. Mas o que é desolador é o pensamento de que o oposto da doença do normal não é simplesmente a saúde do doente, mas sim que esta na maior parte das vezes representa apenas de uma outra maneira o esquema da mesma desgraça (ADORNO, 2003, p. 1746-7; 1993, p. 51).

Nesse quadro, Horkheimer e Adorno vão afirmar que o corpo permanecerá um cadáver ${ }^{16}$, ainda que seja muito exercitado, na medida em que o corpo físico (Körper) não pode mais ser reconvertido em corpo vivo (Leib), como prega certa tradição vitalista e romântica, cuja representação contemporânea pode ser encontrada nos campos e praias de nudismo e na sedução de várias terapias alternativas. Se sua reconversão seria impossível, porque a reificação do corpo, sua transformação em algo de morto, foi parte do processo perene que transformou a natureza em matéria bruta, então a alusão à semelhante projeto não soa para Adorno apenas como um despropósito, mas, sobretudo, como um discurso ideológico, de matiz fortemente regressiva, falseador e justificador da injustiça e da violência praticada contra a natureza, nesse caso, contra o próprio corpo. Vale a pena retomar a passagem da Dialética do esclarecimento na qual Horkheimer e Adorno expõem essa questão de modo bastante claro:

O corpo se vê de novo escarnecido e repelido como algo inferior e escravizado, e, ao mesmo tempo, desejado como proibido, reificado [Verdinglichte], alienado. É só a cultura que conhece o corpo como

\footnotetext{
${ }^{16} \mathrm{Da}$ mesma forma, também a linguagem estaria entronizada com a cadaverização do corpo: "ela [a linguagem] transformou o passeio em movimento e os alimentos em calorias, de maneira análoga à designação da floresta viva [lebendige Wald] na língua inglesa e francesa pelo mesmo nome que significa também 'madeira' [Holz]" (HORKHEIMER; ADORNO, 2003, p. 1530-1531; 1985, p. 219).
} 
coisa [Ding] que se pode possuir; foi só nela que ele se distinguiu do espírito, quintessência do poder e do comando, como objeto, coisa morta, "corpus". Com o auto-rebaixamento do homem ao corpus, a natureza vinga-se do fato de que o homem a rebaixou a um objeto de dominação, de matéria bruta (HORKHMEIR; ADORNO, 2003, p. 1526-1527; 1985, p. 217; grifo nosso).

\section{Uma consideração final - sujeito e objeto no corpo}

Se, por um lado, o sujeito racional, no seu movimento de constituição, precisou se diferenciar da natureza sob pena de perecer, por outro ele segue sendo natureza diferenciada. O problema, dirá Adorno, é que, ao compreendê-lo como o oposto do que é, o sujeito se enreda numa rude regressão à natureza e no esquecimento de si como parte (da) natureza. Esta radical separação entre sujeito e objeto, marca do processo de constituição da cultura e da civilização e manifestação como esquecimento da dor desse mesmo processo, encontra nas práticas corporais, como já mencionado, um paradoxo, que é o de fazer encontrar ambos polos da equação em um mesmo lugar e tempo, a experiência somática.

O "interesse pelo corpo" do qual nos falam Adorno e Horkheimer (2003, p. 1524 ; 1985 , p. 215-6) percorre clandestina e subterraneamente a história da civilização ocidental, de forma a acabar por converter o somático no lócus da subjetividade, ou do que dela restou. Dessa maneira, é o corpo, não como possibilidade mimética, recordação de nossa condição de natureza e indeterminação, mas como mera naturalidade culturalmente desqualificada, que acaba por assumir o lugar da imaginação no processo de constituição subjetiva. Essa naturalidade desqualificada parece não apenas permanecer, mas se acirrar, mesmo considerando todo o investimento que se faz sobre o corpo contemporaneamente, incluindo também aquele produzido no âmbito da sua educação, da sua escolarização. Nesse contexto, é possível pensar em processos de (des) subjetivação que se materializam na relação com o corpo, para os quais se desenvolve uma espécie de pedagogia (BASSANI; VAZ, 2008, p. 113114), que se organiza de forma complexa e contraditória, estruturandose nos mais variados tempos e espaços sociais. No caso específico dos 
ambientes formais de educação, como a escola, essa pedagogia do corpo se faz presente no ensino e prática dos esportes e nas aulas de Educação Física, mas também nos momentos mais insuspeitos, como nos cuidados higiênicos, medicalizações e dispositivos que incidem sobre a dimensão somática em todos os momentos do processo de escolarização. ${ }^{17}$

É exatamente nesse quadro que podemos ler, por exemplo, as assertivas de Adorno sobre o caráter ambíguo das práticas corporais e dentre elas especialmente o esporte. A ambiguidade do esporte reside, segundo essa interpretação, no papel que pode desempenhar em relação ao reconhecimento de nossa dimensão de natureza, por um lado, e no domínio estremado do corpo, como natureza desqualificada, por outro. Nesse sentido, ao mesmo tempo em que poderia ter um efeito contrário à barbárie e ao prazer em infringir violência, permitiria, paradoxalmente, fomentar a agressão e o sadismo. Nas palavras de Adorno:

por um lado ele [o esporte] pode ter efeito contrário à barbárie e ao sadismo, por intermédio do fairplay, do cavalheirismo e do respeito pelo mais fraco. Por outro, em algumas de suas modalidades e procedimentos, ele pode promover a agressão, a brutalidade e o sadismo, principalmente no caso dos espectadores, que pessoalmente não estão submetidos ao esforço e à disciplina do esporte; são aqueles que costumam gritar nos campos esportivos (ADORNO, 2003, p. 8528; 1995a, p. 127).

Adorno irá uma vez mais se referir diretamente, no âmbito dos seus escritos sobre educação, a um certo caráter aristocrático do esporte, mais precisamente no debate com Hellmut Becker, intitulado Educação contra a barbárie (ADORNO, 1995a, p. 155-168). Nesse texto, ao discorrerem sobre a competição, como elemento pedagógico estimulado pelos próprios professores para melhorar a aprendizagem das crianças sobre diversos conteúdos, Adorno e Becker afirmam que ela é um princípio, no fundo,

\footnotetext{
${ }^{17}$ Sobre os dispositivos pedagógicos implicados na produção de uma infância e um sujeito "higienizado", e que tomam o corpo como alvo preferencial nos tempos e espaços escolares, conferir, entre outros, Faria Filho (2000), Gondra (2004), Gondra; Rocha (2000), Taborda de Oliveira (2007) e Vago (2004).
} 
contrário à educação humana, e, portanto, representa em si um elemento de educação para a barbárie. Nesse contexto, Adorno (2003) afirma que com a competição é possível, quando muito, educar esportistas, mas não pessoas desbarbarizadas. Corroborando com afirmação de Becker, qual seja, a de que a recusa das ideias exageradas de competição na educação constitui um aspecto em que se pode fazer algo de fundamental com relação à desbarbarização, Adorno (1995a) destaca que é preciso desacostumar as pessoas de se darem cotoveladas. Afirma ainda que na noção de fair play, presente no ideário do sistema educacional inglês, encontra-se momentos de uma consideração segundo a qual a motivação desregrada da competição conteria algo de desumano e neste sentido haveria um bom motivo em se aproveitar o ceticismo do ideal formativo inglês frente ao supostamente "saudável" desejo de sucesso (ADORNO, 1995a, p. 162). Para ele, assim como também para Becker, seria necessário diminuir o peso das formas muito primitivas e marcadas da competitividade, especialmente nas práticas esportivas na escola, o que poderia levar, na opinião de ambos, a um predomínio do aspecto lúdico frente ao chamado desempenho máximo (ADORNO, 1995a, p. 162-3). Isso seria, diz Adorno, uma inflexão particularmente humana, contrária, inclusive, ao espírito do tempo presente.

Essa leitura do esporte como fenômeno ambíguo, e o correspondente elogio ao fair play, indicam dois elementos importantes da reflexão de Adorno. Em relação a este último, trata-se de uma estratégia metodológica, irônica, já presente em Minima Moralia (ADORNO, 2003; 1993): o elogio do etos aristocrático não pretende expressar um saudosismo em relação à um tempo pregresso, como faria um crítico conservador, mas retomar a irônica lembrança de que outrora ainda havia um sujeito autônomo, de forma que a esperança de sua superação dialética (Aufhebung) ainda se colocava. No contemporâneo, no entanto, essa possibilidade, como Adorno (2003, p. 8516-8544; 1995a, 119-138) aponta em Educação após Auschwitz, está suspensa, seja porque o sujeito histórico não realizou a superação da filosofia (ADORNO, 2003, p. 2830; 2009, p. 11), ou ainda porque seu momento transcendental se revelou expressão da própria antinomia (ADORNO; HORKHEIMER, 2003; 1985). 
No que diz respeito à ambiguidade do esporte, esta expressão dialética do domínio da natureza, síntese do espetáculo mediado pela indústria cultura e da possibilidade de um impulso que respeite a diferença com o (corpo do) outro, tema presente não apenas no texto supracitado, mas no material adjunto à Dialética do esclarecimento - O esquema da cultura de massas (ADORNO, 2003, p 1579-1641; 2007, p. 281-316), encontramos uma indicação interessante para pensar o ensino das práticas corporais como rememoração da natureza no sujeito. Se o humano, para poder dominar a natureza, precisou alienar-se de sua vitalidade primária e esquecer o sofrimento proveniente dessa violência, é pelo reconhecimento da repressão em seu próprio corpo que se pode ter alguma esperança de se alcançar uma relação reconciliadora com ele.

\section{Referências}

ADORNO, T. W. Dialética negativa. Tradução de Marco Antonio Casanova. Rio de Janeiro: Jorge Zahar, 2009.

. Dialéctica de la ilustración. Tradução de Joaquín Chamorro Mielke. Obra completa, 3. Madri: Akal, 2007.

. Escritos Sociológicos I. Tradução de Agustín González Ruiz. Obra completa, 8. ed. Madrid: Akal, 2004a.

Berlin: Directmedia, 2003.

. Gesammelte Schriften. Frankfurt am Main: Suhrkamp, 1986;

. Educação e emancipação. Tradução de Wolfgang Leo Maar. Rio de Janeiro: Paz e Terra, 1995a.

. Palavras e Sinais: Modelos Críticos 2. Tradução de Maria Helena Ruschel. Petrópolis: Vozes, 1995 b.

. Minima Moralia: reflexões a partir da vida danificada. Tradução de Luiz Eduardo Bicca. 2. ed. São Paulo: Ática, 1993.

. Os pensadores (Adorno e Horkheimer). São Paulo: Abril Cultural, 1991.

ALMEIDA, M. J. A Liturgia Olímpica. In: SOARES, C. (Org.). Corpo e História. 3. ed. Campinas: Autores Associados, 2006. p. 79-108. 
ALMEIDA, G. A. de. Nota preliminar do tradutor. In: HORKHEIMER, M.; ADORNO, T. W. Dialética do esclarecimento: fragmentos filosóficos. Rio de Janeiro: Jorge Zahar, 1985. p. 7-8.

ÁRIES, P. ; DUBY, G. Coleção História da Vida Privada. São Paulo: Companhia de Bolso, 2009.

BASSANI, J. J., VAZ, A. F. Técnica, corpo e coisificação: notas de trabalho sobre o tema da técnica em Theodor W. Adorno. Educação \& Sociedade, Campinas, v. 29, n. 102, p. 99-118, 2008.

BASSANI, J. J.; TORRI, D.; VAZ, A. F. Sobre a presença do esporte na escola: paradoxos e ambigüidades. Movimento. Porto Alegre, v. 9, n. 2, p. 89-112, maio/ago. 2003.

BENJAMIN, W. Obras escolhidas III: Charles Baudelaire um lírico no auge do capitalismo. 2. ed. São Paulo: Brasiliense, 1991.

. Obras escolhidas I: magia e técnica, arte e política. 4. ed. São Paulo: Brasiliense, 1985.

COMENIUS, J. A. Didática Magna. Tradução de Ivone Castilho Benedetti. 3. ed. São Paulo: Martins Fontes, 2006.

DUARTE, R. Mimesis e Racionalidade. São Paulo: Loyola, 1993.

FARIA FILHO, L. M. Para entender a relação escola-família: uma contribuição da história da educação. Revista São Paulo em Perspectiva, São Paulo, v. 14, n. 2, p. 44-50, 2000.

FREITAS, V. Adorno e a Arte Contemporânea. Rio de Janeiro: Zahar, 2003.

FREUD, S. O mal-estar na civilização. Rio de Janeiro: Imago, 1997. . Lembrar escrever esquecer. São Paulo: Editora 34, 2006. . Sete aulas sobre linguagem, memória e história. Rio de Janeiro: Imago, 1997.

GIACÓIA JUNIOR, O. Esquecimento, memória e repetição. Psicologia \& Sociedade, São Paulo, v. 13, n. 2, p. 58-91, jul./dez. 2001.

GONDRA, J. G. Combater a 'Poética pallidez': a questão da higienização dos corpos. Perspectiva. Revista do Centro de Ciências da Educação da UFSC, Florianópolis, v. 22, n. 1, p. 121-161, jul./dez. 2004. 
GONDRA, J. G.; ROCHA, H. Estratégias de higienização da organização escolar - A questão do corpo (1852-1902). Boletín de La Sociedad Argentina de Historia de La Educación, Argentina, v. 1, n. 1, p. 33-38. 2000.

HORKHEIMER, M. Eclipse da razão. São Paulo: Centauro, 2000.

. Teoria crítica I: uma documentação. São Paulo: Perspectiva, 1990.

HORKHEIMER, M.; ADORNO, T. W. Dialektik der Aufklärung: Philosophische Fragmente. In: ADORNO, T. W. Gesammelte Schriften. Frankfurt am Main: Suhrkamp, 1986; Berlin: Directmedia, 2003. p. 10871643.

. Dialética do Esclarecimento: fragmentos filosóficos. Tradução de Guido Antônio de Almeida. Rio de Janeiro: Zahar, 1985.

JAY, M. As Idéias de Adorno. Tradução de Adail U. Sobral. São Paulo: Cultrix; Ed. da USP, 1988.

LINHALES, M. A. A produção de uma forma escolar para o esporte: os Projetos Culturais da Associação Brasileira de Educação (1926-1935) como indícios para a Historiografia da Educação Física. In: TABORDA DE OLIVEIRA, M. A. (Org.). Educação do Corpo na Escola Brasileira. Campinas: Autores Associados, 2006. p. 93-110.

LOVISOLO, H. Prolongar a vida: da didática à fisiologia. Revista Brasileira de Ciências do Esporte, Florianópolis, v. 21, n. 1, p. 164-170, Set. 1999.

LÖWY, M.; VARIKAS, E. A crítica do progresso em Adorno. Revista de Cultura e Política. São Paulo, n. 27, p. 201-215, dez. 1992.

LUKÁCS, G. História e consciência de classe. São Paulo: Martins Fontes, 2001.

MARCUSE, H. A noção de progresso à luz da psicanálise. In: Cultura e psicanálise. São Paulo: Paz e Terra, 2001. p. 112-138. . Tecnologia, guerra e fascismo. São Paulo: Ed. da UNESP, 1999. . A ideologia da sociedade industrial: o homem unidimensional. 4. ed. Rio de Janeiro: Zahar Editores, 1973.

NIETZSCHE, F. W. Genealogia da moral: uma polêmica. São Paulo: Companhias das Letras, 1998.

PLATÃO. A República. São Paulo: Nova Cultural, 2004. 
RAMOS, C. O ressentimento do guerreiro: reflexões sobre corpo e educação a partir do pensamento de Theodor Adorno e da Psicanálise. Interações, São Paulo, v. 11, n. 3 p. 09-28, jun. 2006.

TABORDA DE OLIVEIRA, M. A. Currículo e educação do corpo: história do currículo da instrução pública primária no Paraná (1882-1926). In: PEDRAZZA, Zandra (Org.). Estudios sobre el cuerpo en la América Latina. Bogotá: Universidad Los Andes, 2007. p. 70-99.

VAGO, T. M. Da ortopedia à eficiência: a gymnastica e as exigências da "vida moderna" (Minas Gerais, 1906-1930). Revista Movimento, Porto Alegre, v. 10, n. 3, p. 77-97, set./dez. 2004.

VAZ, A. F. Notas Conceituais sobre Mímesis e Educação do Corpo em Max Horkheimer e Theodor W. Adorno. In: PUCCI, Bruno; GOERGEN, Pedro; FRANCO, Renato. (Org.). Dialética Negativa, Estética e Educação. Campinas: Alínea, 2007, p. 189-202.

. Técnica, Esporte, Rendimento. Revista Movimento, Porto Alegre, v. VII, p. 87-99, jan./jul. 2001.

. Treinar o corpo, dominar a natureza: notas para uma análise do esporte com base no treinamento corporal. Cadernos CEDES - Corpo e Educação, Campinas, v. 19, n. 48, p. 89-108, Ago. 1999.

VAZ, A. F.; BASSANI, J. J.; SILVA, A. S. da. Identidades e rituais na educação do corpo na escola: um estudo em aulas de educação física no ensino fundamental. Motus Corporis, Rio de Janeiro, v. 9, n. 2, p. 23-39, nov. 2002.

WILDMANN, D. Begehrte Körper: Konstruktion und Inszenierung des “arischen” Männerkörpers im "Drittenreich”. Würzburg: Königshausen \& Neumann, 1998. 
